\title{
Anger as Spanish funder claws back science money
}

\section{Research institutes' unused cash reserves wiped amid budget crisis.}

\section{Nuño Domínguez}

05 July 2013

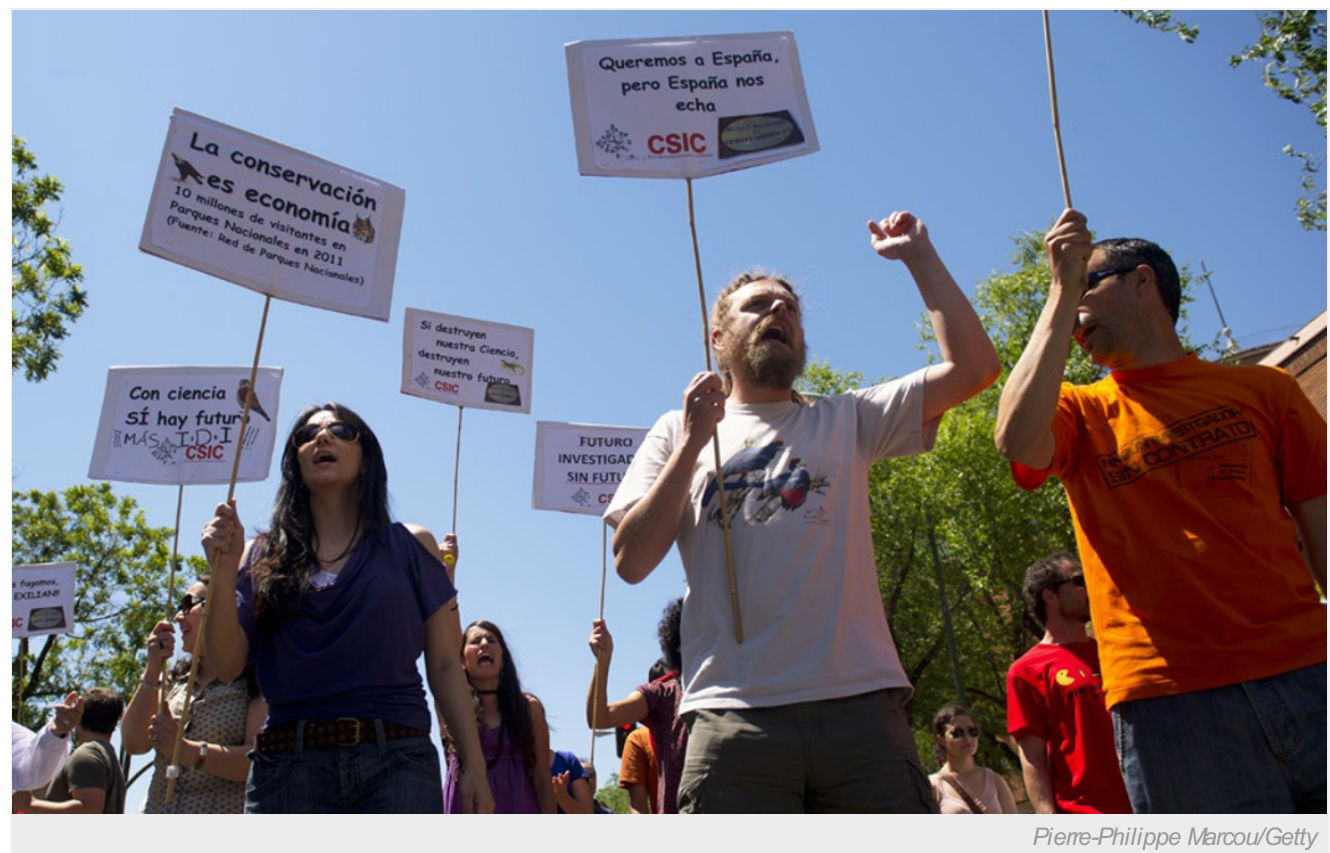

Spanish scientists protest against government cuts to scientific research in Madrid on 14 June 2013.

Researchers at institutes funded by Spain's National Council for Scientific Research (CSIC) are outraged over a move to take back unspent money from their budgets. The council's decision is the latest development in Spain's burgeoning science crisis.

Any institute that has been frugal with its funding and has saved money will now find some of those savings absorbed back into the CSIC's centralized pot. The CSIC, based in Madrid, is Spain's largest scientific organization, with 15,000 employees, some 6,000 of whom are scientists. Its centralized finance model handles national and European Union research money for more than 100 institutes.

But the CSIC is in the middle of its largest budget crisis in years. Since 2010, the funding body has had to deal with large budget cuts imposed by the government, with a total reduction of $€ 500$ million (US\$642 million), according to CSIC president Emilio Lora-Tamayo. Last week, the government injected $€ 25$ million into the council. However, the CSIC needs $€ 100$ million to make it to the end of the year.

The move to seize unspent reserves is meant to keep the council running until "early or mid-October", Lora-Tamayo said last week during a meeting with the council's directors. He said that national and European Union research funding that has been awarded to CSIC institutes would be frozen, and that savings made before January 2012 will remain in the council's pot.

\section{Damage control}

The decision has enraged many scientists. "The current spending limit is supposed to keep our institute running until years' end, but with the new amount set for my institute we would not make it to September," says Juan Lerma, director of the CSIC's Institute of Neuroscience in Alicante.

Hardest hit are those who have saved part of their project's money to buy equipment or issue contracts to junior researchers. "Our savings after January 2012 are frozen and those from earlier projects have just disappeared," says Maxi San Miguel, director of the Institute for Cross-Disciplinary Physics and Complex Systems (IFISC) in Palma de Mallorca, a joint research institute of the CSIC and the University of the Balearic Islands. "We estimate our loss at around $€ 300,000$, and that's for a relatively small institute like ours," he says. 
Lora-Tamayo says that money awarded to researchers before January 2012 but not withdrawn from the council's pot are "indistinguishable", meaning that it is not possible to tell where it came from. On Tuesday, science news website Materia reported that Lora-Tamayo had written to institutes saying that they should "cancel" those savings from their books, but did not specify the total amount. Asked for comment, the CSIC's head of communications, Ainhoa Goñi, did not respond to Nature.

Nature I doi:10.1038/nature.2013.13345 